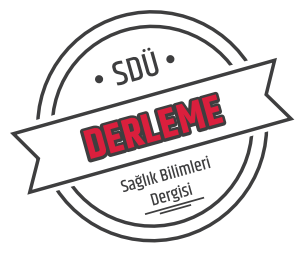

Sdü Sağlık Bilimleri Enstitüsü Dergisi / Cilt 8 Sayı 2 / 2017

\title{
Maloklüzyonun Psikososyal Etkileri ve Çocuklarda Ortodontik Tedavi Görme İsteği
}

\section{The Psychological Effects of Malocclusion and the Desire of Orthodontic Treatment in Children}

Esra Karaağaç${ }^{1}$, Çiğdem Küçükeşmen ${ }^{1}$

${ }^{1}$ Süleyman Demirel Üniversitesi, Diş Hekimliği Fakültesi, Pedodonti AD, Isparta, Türkiye.

\section{Özet}

Toplumda en yaygın olarak görülen ağız diş sağlı̆̆ problemlerinden biri olan maloklüzyon, hastanın sosyal hayatında psikolojisini etkileyen bazı kısitlamalara neden olabilmektedir. Hastaların, ortodontik tedaviden beklentileri; çiğneme, konuşma gibi oral fonksiyonlarının iyileşmesi ile birlikte dişsel estetiklerinin de düzelmesi ve psikososyal durumlarının geliştirilmesidir.

Bireylerin ortodontik bozukluklarının ne kadar farkında oldukları, dişlerinin estetik görünümlerinden duydukları memnuniyet düzeyleri, ortodontik tedaviden ne gibi beklentilere sahip oldukları ve bu ortodontik düzensizliklerin hastaların sosyal yaşamlarına olan etkilerinin anlaşılması bakımından hastaların ortodontik tedavi görme isteklerinin nedenlerinin belirlenmesi büyük önem taşımaktadır.

Anahtar kelimeler: Maloklüzyon, Ortodontik Tedavi Görme İsteği, Estetik, Psikolojik Etki

\begin{abstract}
Malocclusion that is one of the most common oral and dental health problems in the community, can cause some limitations affecting the psychology of the patient's social life. Patients' expectations for orthodontic treatment is improvement of oral functions such as chewing, speech and the development of the psychosocial situation.

It is important to determine the causes of patients' orthodontic treatment desires in terms of their level of awareness of their orthodontic disorders, their level of satisfaction with their aesthetic appearance, their expectations from orthodontic treatment, and their understanding of the effects of these orthodontic disorders on the social lives of patients.
\end{abstract}

Key words: Malocclusion, Desire of Orthodontic Treatment, Aesthetic, Psychological Effect

\section{Giriş}

Ağız diş sağlığını etkileyen, çürük oluşumunu arttıran, periodontal hastalıklara ve temporomandibular eklem bozukluklarına neden olan, en yaygın ağı sağlığ problemlerinden biri olan maloklüzyonun, psikolojik, kültürel ve sosyal yönleri, ağız-diş ve genel vücut sağlığının ayrılmaz bir parçası olarak görülmektedir (1).

\section{Maloklüzyonun Psiko-Sosyal Etkileri}

Maloklüzyonun en önemli etkilerinden biri, dento-fasiyal estetiğin bozulmasıyla birlikte, birey üzerinde oluşturduğu psiko-sosyal etkidir. $\mathrm{Bu}$ durum hastanın genel yaşam kalitesiyle de bağlantılıdır $(1,2)$. Hekimler, maloklüzyonun hasta üzerindeki psiko-sosyal etkisinin ortodontik tedavi için en güçlü motivasyon araçlarından biri olduğunu belirtmektedirler (3).

Çocuklar için ideal bir dento-fasiyal estetiğe sahip olmak, sadece estetik olarak daha güzel olmak anlamına gelmeyip, toplumda yaşıtları, öğretmenleri ve diğer bireyler tarafından, sosyal olarak daha fazla kabul görmek anlamına da gelmektedir $(4,5)$. Hastaların çoğunluğu, ortodontik tedavi sonrasındaki beklentilerini, iyi bir oral fonksiyona sahip olmaktan ziyade, 'psikolojik olarak kendini daha iyi hissetmek' olarak ifade etmişlerdir (6).

Estetik kaygıların, hastaların yaşam koşullarını etkilemesinden dolayı, maloklüzyonun estetik boyutunun, bireylerin sosyal yaşamlarında küçümsenmeyecek kadar önemli bir yer kapladığı vurgulanmaktadır (7). Zayıf dentofasiyal estetiğin (artmış overjet, ön dişler arasındaki boşluklar gibi) hastanın yaşam kalitesi üzerindeki psikolojik ve sosyal etkileri, hastada fizyolojik problemlerden daha ciddi sorunlar oluşturabilmektedir (8). Bu bireylerin alay konusu olmalarına, takma isimlerle çağrılmalarına ve toplum içinde uğradıkları sosyal ayrımcılığa daha çok maruz kalmalarına neden olmaktadır (7). Yapılan bir çalışmada, 9-13 yaşları arasındaki çocukların \%7'sinin, dişlerinin estetik görünümlerindeki bozukluklardan dolayı, haftada en az bir kez bile olsa, alay edilmeye maruz kaldıkları ortaya konmuştur (9).

Herhangi bir cinsiyet ayrımı belirtilmeksizin ortodontik düzensizlikleri olan bireylerin, gülerken dişlerini gizledikleri, konuşurken dişleri gözükmesin diye elleriyle ağızlarını kapattıkları, fotoğraflarında da dişlerinin gözükmesini istemedikleri belirtilmiştir (10). Dişlerinin görüntüsünden
DOI: $10.22312 /$ sdusbed.306301

Müracaat tarihi: 09.03 .2017

Kabul tarihi: 24.03.2017

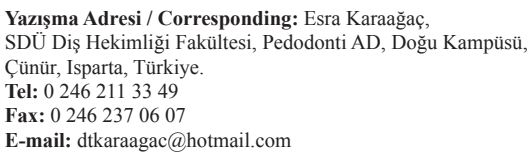


dolayı ağlama ve gülmekten kaçınma gibi, maloklüzyonun hasta üzerindeki psikolojik etkilerinin, çocuklarda yaşlılar ve yetişkinlere göre daha yaygın olduğu bildirilmiştir (11).

Bellot-Arcís ve ark., 12-15 yaşları arasındaki 627 çocukta maloklüzyonun psiko-sosyal etkisini değerlendirmek, maloklüzyonun şiddetiyle ilişkisini, adölesanlarda sosyal sınıf ve cinsiyetin etkisini belirlemek için yaptıkları bir çalışmada, dişsel estetiğin kişide yarattığı psiko-sosyal etkinin maloklüzyonun şiddetiyle arttığını rapor etmişlerdir (12).

Cinsiyet, adolesanlarda maloklüzyonun hastalar üzerindeki psiko-sosyal etkilerinde farklılıklar yaratmaktadır (12). Maloklüzyonun psiko-sosyal etkilerinin, kılarda erkeklere göre daha fazla olup, yaşam kalitelerini etkilediği gösterilmiştir (12-14). Maloklüzyon söz konusu olduğunda, yaşam kalitesi üzerine olan etkileri ile yaşları arasında negatif bir ilişki olduğu da bildirilmiştir. Maloklüzyonun birey üzerindeki etkilerinin, yaş arttığı zaman azaldığı da görülmüştür (15).

Artmış overjet, dişlerin yer değişimi ve artmış örtülü kapanış, hasta üzerinde daha fazla psiko-sosyal etkiye sahip oklüzal durumlar olarak değerlendirilmektedir (12). Eksik, renklenmiş, çarpık veya estetik olmayan dişlere sahip bireylerin, yıkıcı özeleştirilere maruz kaldıkları rapor edilmiştir (14). Örneğin, eksik dişlere sahip hastaların, düz ve beyaz dişlerin estetik görünümlerinde en önemli özellik olduğunu düşünmelerinden dolayı, gülümsemekten kaçınma veya gülümsemelerini değiştirme, kafalarını başka yöne çevirme veya eksik dişin/dişlerin bıraktığı boşluğun önüne, dillerini yerleştirme gibi çeşitli gizleme stratejileri geliştirdikleri belirlenmiştir (16).

\section{Hastaların Ortodontik Tedavi Görmek Istemelerinin Nedenleri}

Çeşitli sosyal, ekonomik ve kültürel faktörler, ortodontik tedavi ihtiyacının kişisel olarak algılanma düzeylerini ve ortodontik tedavi görme isteklerini etkileyebilmektedir (1719). Hastaların ortodontik tedavi görme istekleri, ihtiyaçtan çok estetik talepten kaynaklanmaktadır (20). Özellikle genç bireyler çekici bir dişsel estetik görünümün, kendileri için önemli olduğunu belirtmektedirler (21). Yapılan bir çalışmada, estetik nedenlerden dolayı ortodontik tedavi görmek için başvuranların sayısı \%80 olarak belirlenirken, çiğneme ve konuşma gibi fonksiyonel nedenlerden dolayı başvuranların sayısı, \%20 gibi daha düşük bir değer olarak bildirilmiştir (22).

Adölesan bireylerin, ortodontik tedaviden en önemli beklentileri, ortodontik tedavi sonucunda dişlerinin düzgün sıralanmış olması ve gülümsemeleri sırasında dişlerinin daha güzel görünmesinin sağlanmasıdır (18, 23, 24). Genel yüz görünümü için, düzgün sıralanmış dişlerin önemli olduğu, çocuklar tarafından belirtilmiştir $(25,26)$. Üst ve alt dişlerin çapraşıklıkları ve/veya düzgün sıralanmamaları, daha iyi bir dişsel estetik görünümüne sahip olma isteğinde ana neden olarak gösterilmiştir (18). Yapılan çalışmalarda, çocuk hastaların üçte birinin görünümleri için sağlıklı ve düzgün sıralanmış dişlerin önemli olduğunu düşündükleri bildirilmiştir (19,27). Senegal'de ortodontik tedavi arayışında olan hastaları motive eden faktörlerden en önemlisinin; 12 13 yaşlarındaki 665 çocuğun \%23,8'ında ve Nijerya'da yaş ortalaması 15 olan adölesanların \%21,6'sında düzgün dişlere sahip olma isteğinin olduğu bildirilmiştir $(23,28)$.

Bazı bireyler için küçük düzensizlikler çok rahatsız edici olabilirken, bazıları için şiddetli maloklüzyonlar o kadar da endişe verici olmayabilmektedirler (29). Örneğin; Güney Amerika nüfusunda, maksiller overjetin ve ön diaestemanın, algılanan dişsel estetik görünümü negatif olarak etkilemediği görülürken; Asya topluluklarında ise, artmış overjet dental estetiği etkileyen en önemli oklüzal faktör olarak algılanmaktadır. Bu nedenden dolayı, ortodontik tedavi görme isteğinin değerlendirilmesi ve hastaya önerilecek olan tedavi yönteminin nasıl olacağı; diş hekimlerinin, pedodontistlerin veya ortodontistlerin verebileceği profesyonel görüşleri gerektirmektedir (30).

Hastaların ortodontik tedavi görme isteklerinin, çeşitli popülasyonlar arasında da farklılıklar gösterdiği görülmüştür (18, 23, 31). Örneğin; Ürdün'de 12-14 yaşları arasındaki 1002 çocuğun \%49'unun, Kuveyt'te 14-18 yaşları arasındaki 1076 çocuğun \%36'sının ve Brezilya'da 12 ve 13 yaşlarındaki çocukların \%69,6'sının, ortodontik tedavi görmeyi istedikleri belirlenmiştir (32-34). Çocuklardaki ortodontik tedavi görme isteklerinin fazla olmasının nedenlerinin, bu çalışmalarda yer alan çalışma gruplarındaki çocukların ortodontik tedavilerle ilgili olarak bilinç düzeylerinin artmış olmasına ve estetik görünümlerinden duydukları memnuniyetsizlik düzeylerinin fazla olmasına bağlı olmuş olabileceği düşünülebilir.

Isırma ve çiğneme, temporomandibular eklem rahatsızlıkları, başağrısı, profesyonel birinden tavsiye almak, hastalar tarafindan ortodontik tedavi görme isteği için belirtilen diğer nedenler arasındadır (13). Bazı hastalar, 'iyi 1sıramıyorum' veya ‘çiğneyemiyorum' gibi fonksiyonel bozukluklardan (\%14) dolay1, ortodontik tedavi görmeyi istediklerini ifade etmişlerdir (18). Bu hastalarda; ortodontik tedavinin öneminin belirlenmesinde, çiğneme veya konuşma güçlüğü gibi fonksiyonel yönlerin, çapraşıklık gibi estetik özelliklerden daha önemli olduğu da vurgulanmaktadır (35).

Ortodontik tedavi görmek isteme nedenleri arasında, diş ağrısı veya diş renklenmeleri de hastalar tarafından ifade edilmiştir. $\mathrm{Bu}$ durum, hastaların ortodontik tedavinin içeriği hakkındaki bilinçsizliğini ve hasta eğitiminin eksikliğini göstermektedir (18).

Çevresinde ortodontik tedavi gören arkadaşları ya da akrabaları olması da çocuk ve/ veya adelösan bireylerde ortodontik tedavi görme isteği nedenleri arasındadır. Yapılan bir çalışmada, bütün yaş gruplarındaki hastaların $\% 5$ 'inden daha azının yaşıtlarının etkisinin bir sonucu olarak ortodontik tedavi görmeyi istedikleri belirtilmiştir (13).

Türkiye'de yaşları 6 ve üzerinde olan 374 birey arasında yapılan bir araştırmada ise, hastaların \%69,3'ü çarpık dişlerini düzelttirmek, \%9,9'u iyi bir estetik görünüme kavuşmak, \%5,3’ü yemek yeme fonksiyonlarını geliştirmek, \%2,7'si konuşmalarını düzeltmek, \%1,1'i ise daha güzel bir gülüşe sahip olmak için ortodontik tedavi görmeyi istediklerini 
belirtmişlerdir (22).

Hastalara dişleri ile ilgili değişmesini istedikleri özellikler sorulduğunda, Yemen' de yapılan bir çalışmada hastaların \%37,6'sı dişlerinin rengi, \%36,9'u sıralanmas1, \%6's1 ise büyüklükleri olarak belirtmişlerdir (19). Nijerya'da ise, 12-18 yaşları arasındaki adölesanların \%64,9'u dişlerinin rengini, \%21,6'sı sıralanmasını, \%13,5'i ise büyüklüklerini değiştirmek istediklerini ifade etmişlerdir (23). Polonya' da 12 yaşındaki çocukların \%65,4’ü dişleriyle ilgili bazı özellikleri değiștirmek istediklerini belirtirlerken, bu hastaların $\% 55,4$ 'ü dişlerinin sıralanmasını, \%43'ü rengini, \%1,6's1 ise büyüklüğünü değiştirmek istediklerini ifade etmişlerdir (36).

12-14 yaşları arasındaki çocuklarda, Karaağaç ve Küçükeşmen'in yaptıkları çalışmada; çocukların büyük çoğunluğu $(\% 82,9)$ dişleriyle ilgili bazı özellikleri değiştirmek istediklerini belirtmişlerdir (37). Dişleriyle ilgili olarak hoşlanmadıkları özellikleri; \%55,8'i dişlerinin düzensizliği (yamukluğu), \%7,6'sı dișlerindeki boșluklar (ayrıklıklar), \% 7,6'sı dişlerindeki çürükler, \%5,8'i dişlerinin şekli, \%3,8'i üst çenenin önde konumlanması, \%3,6'sı çapraşıklık, $\% 2,9$ 'u ise alt çenenin önde konumlanması ve geri kalanları kırık, üst dişlerin önde olması, ön açıklık, diştaşı, diş ağrısı, kötü görünmesi, diş eksikliği, çene ağrısı, dişlerinin çıkmaması ve dişeti kanaması olarak bildirmişlerdir.

\section{Hastaların Ortodontik Tedavi Görmek Istemelerinin Cinsiyetlere Göre Değerlendirilmesi}

Ortodontik tedavi görme istekleri cinsiyetlere göre karşılaştırıldığında, erkeklerin kızlara göre ortodontik tedaviden beklentilerinin daha farklı olduğu belirtilmiştir. Hem erkek hem de k1z hastalar, fasiyal görünümlerini ve fonksiyonlarını geliştirmek istemelerine rağmen, erkek hastaların daha fazla motivasyona sahip oldukları görülmüştür (38). Kızların, erkeklere göre dişlerinin düzgün sıralanması ile ilgili daha fazla endişe duydukları rapor edilmiştir (19, 33, 39-42). Brezilya' da 12 ve 13 yaşlarındaki çocuklarda, tedavi görme isteğinin kılarda erkeklere göre özellikle çiğneme güçlüğünden ve estetik görünümlerindeki memnuniyetsizlikten dolayı daha fazla olduğu belirtilmiştir (34). Adölesan dönemde, kızların maloklüzyonlarının estetiği ile ilgili daha çok endișe duydukları, erkeklerin ise daha çok dişlerinin fonksiyonel yönleri ile ilişkili olarak endişelendikleri belirtilmiştir (5). Bunun aksine, 10-12 yaşları arasındaki çocuklarda yapılan bir çalışmada, dişlerinin görüntüsünden memnun olmama ve dişlerinin düzgün sıralanması için tedavi görme istekleri ile cinsiyetler arasında önemli farklılıklar gözlemlenmemiștir (43).

Yaşın artmasıyla beraber, kızların büyük çoğunluğu dişlerinin estetik görünümünden memnun olmadıklarını belirtirken, erkekler arasında da görünümlerini geliştirmek isteyenlerin sayısında artış olduğu görülmüştür (15). Bunun aksine, Zreaqat ve ark., yaptıkları çalışmada, cinsiyet ile ortodontik tedavi görme isteği arasında farklılık gözlemlememişlerdir (44).

\section{Hastaların Ortodontik Tedavi Görmek Istemelerinin Yaş Gruplarına Göre Değerlendirilmesi}

Yaş gruplarına göre ortodontik tedavi görme isteklerinin karşılaştırıldığı Malezya'da yapılan bir çalışmada, yaşın artmasıyla birlikte, ortodontik tedavi için çocukların daha istekli oldukları ve dişlerinin görünümünden memnun olmayanların sayısının ise arttığı bildirilmiştir (44). Benzer sonuçlar, Birkeland ve ark. ve Bos ve ark. tarafindan da rapor edilmiştir $(42,45)$. Bireylerin dişlenme dönemlerine göre karşılaştırılmasında; 6-9, 10-12 ve 13 yaş ve üzeri gruplarda ortodontik tedavi görme isteği için kliniğe en çok başvuran hastaların 13 yaş ve üzerinde oldukları gözlemlenmiştir (22). Yaşın artmasıyla beraber, hastaların kendi ağız sağlıkları ve ortodontik olarak tedavi edilebilirlik üzerindeki karar verme yeteneklerinin de arttığı görülmektedir (44).

\section{Sonuç}

Sonuç olarak, ortodontik tedaviye başlamadan önce hastaların ortodontik tedavi isteklerinin objektif olarak değerlendirilmesinin yanısıra, hastaların ortodontik tedaviden beklentilerinin, dişsel estetik görünümlerini nasıl algıladıklarının, maloklüzyonların hasta üzerindeki psikolojik etkilerinin değerlendirilmesi de büyük önem taşımaktadır.

\section{Kaynaklar}

1. Işık F, Sayınsu K, Trakyalı G, Arun T. Hastanın psikolojik durumunun ya da kişilik özelliklerinin ortodontik tedavi başarısı üzerine etkileri. Türk Ortodonti Derg. 2004; 17(3): 347-353.

2. Perillo L, Esposito M, Caprioglio A, Attanasio S, Santini AC, Carotenuto M. Orthodontic treatment need for adolescents in the Campania region: the malocclusion impact on self-concept. Patient Prefer Adherence. 2014; 8: 353-359.

3. Nayak UA, Winnier J, Rupesh S. The relationship of dental aesthetic index with dental appearance, smile and desire for orthodontic correction. Int J Clin Pediatr Dent. 2009; 2(2): 6-12.

4. Phillips C, Bennett ME, Broder HL. Dentofacial disharmony: psychological status of patients seeking treatment consultation. Angle Orthod. 1998; 68(6): 547-556.

5. Trulsson U, Strandmark M, Mohlin B, Berggren U. A qualitative study of teenagers' decisions to undergo orthodontic treatment with fixed appliance. J Orthod. 2002; 29(3): 197-204.

6. Zhang M, McGrath C, Hagg U. The impact of malocclusion and its treatment on quality of life: a literature review. Int J Paediatr Dent. 2006; 16(6): 381-387.

7. Graber TM, Vanarsdall RL. Orthodontics, Current Principles and Techniques. Second edition. Missouri, Mosby Co. Chapter 1. 1994.

8. Jawad Z, Bates C, Hodge T. Who needs orthodontic treatment? Who gets it? And who wants it? Br Dent J. 2015; 218(3): 99-103.

9. Shaw WC, Gbe MJ, Jones BM. The expectations of orthodontic patients in South Wales and St Louis, Missouri. 
Br J Orthod. 1979; 6(4): 203-205.

10. Klages U, Bruckner A, Zentner A. Dental aesthetics, selfawareness, and oral health-related quality of life in young adults. Eur J Orthod. 2004; 26(5): 507-514.

11. Chen M, Wang DW, Wu LP. Fixed orthodontic appliance therapy and its impact on oral health-related quality of life in Chinese patients. Angle Orthod. 2010; 80(1): 49-53.

12. Bellot-Arcis C, Montiel Company JM, ManzaneraPastor D, Almerich-Silla JM. Orthodontic treatment need in a Spanish young adult population. Med Oral Patol Oral Cir Bucal. 2012; 17(4): 638-643.

13. Wedrychowska-Szulc B, Syryńska M. Patient and parent motivation for orthodontic treatment--a questionnaire study. Eur J Orthod. 2010; 32(4): 447-452.

14. Babalola SS, Dosumu EB, Shino E. Perception of Dental Appearance and its Implication for Workers in Dental Organizations: A Review of Literature. Kamla-Raj. 2014; 17(2): 501-507.

15. Masood Y, Masood M, Zainul NN, Araby NB, Hussain SF, Newton T. Impact of malocclusion on oral health related quality of life in young people. Health Qual Life Outcomes. 2013; 11(25): 1-6.

16. Omar R, Tashkandi E, Abduljabbar T, Abdullah MA, Akeel RF. Sentiments expressed in relation to tooth loss: a qualitative study among edentulous Saudis. Int J Prosthodont. 2003; 16(5): 515-520.

17. Ngom PI, Brown R, Diagne F, Normand F, Richmond S. A cultural comparison of treatment need. Eur J Orthod. 2005; 27(6): 597-600.

18. El-Momani BR, Tarawneh AM. Why Jordanians seek orthodontic treatment? Demand and real need. JRMS. 2014; 21(1): 17-21.

19. Al-Zubair NM, Idris FA, Al-Selwi FM. The subjective orthodontic treatment need assessed with the aesthetic component of the Index of Orthodontic Treatment Need. The Saudi J Dent Res. 2015; 6(1): 9-14.

20. Mandall NA, Wright J, Conboy FM, O'Brien KD. The relationship between normative orthodontic treatment need and measures of consumer perception. Community Dent Health. 2001; 18(1): 3-6.

21. Nguyen SM, Nguyen MK, Saag M, Jagomagi T. The need for orthodontic treatment among Vietnamese School Children and young adults. Int J Dent. 2014; 1: 1-5.

22. Aksoy A. İlk pılot ağız diş hastalıkları hastanesi ortodonti bölümüne başvuran hastaların sosyo-ekonomik profili. S.D.Ü Tip Fak. Derg. 2005; 12(2): 38-45.

23. Aikins E, daCosta O, Onyeaso C, Isiekwe M. Subjective Opinions of Dental Attractiveness and Orthodontic Treatment Need among Nigerian Adolescents. IOSR-JDMS. 2014; 13(8): 43-48.

24. Sayers MS, Newton JT. Patients' expectations of orthodontic treatment: part 2 findings from a questionnaire survey. J Orthod. 2007; 34(1): 25-35.

25. Mugonzibwa EA, Kuijpers-Jagtman AM, Van 't Hof
MA, Kikwilu EN. Perceptions of dental attractiveness and orthodontic treatment need among Tanzanian children. Am J Orthod Dentofacial Orthop. 2004; 125(4): 426-433.

26. Ajayi EO, Ajayi YO. Attitudes to malocclusion in a Nigerian School Population. JMBR. 2006; 5(1): 16-23.

27. Tickle M, Kay EJ, Beam D. Socio-economic status and orthodontic treatment need. Community Dentistry and Oral Epidemiology. 1999; 27(6): 413-418.

28. Ngom PI, Benoist HM, Thiam F, Diagne F, Diallo PD. Influence of orthodontic anomalies on periodontal condition. Odontostomatol Trop. 2007; 30(118): 9-16.

29. Yetkiner E, Vardar C, Ergin E, Yucel C, Ersin NK. Orthodontic Treatment Need, Self-Esteem, and Oral Health-Related Quality of Life Assessment of Primary Schoolchildren: A Cross-Sectional Pilot Study. Turkish J Orthod. 2014; 26(4):182-189.

30. Borzabadi-Farahani A, Borzabadi-Farahani A. Agreement between the index of complexity, outcome, and need and the dental and aesthetic components of the index of orthodontic treatment need. Am J Orthod Dentofacial Orthop. 2011; 140(2): 233-238.

31. Abdullah AAA, Yassin Z, Zamzam N. Reasons for seeking orthodontic treatment: A pilot study. Annal Dent Univ Malaya. 2001; 8: 13-19.

32. Abu Alhaija ESJ, Al-Nimri KS. Al-Khateeb SN. Orthodontic treatment need and demand in 12-14 year-old Jordanian school children. Eur J Orthod. 2004; 26(3): 261263.

33. Kerosuo H, Al Enezi S, Kerosuo E, Abdulkarim E. Association between normative and self-perceived orthodontic treatment need among Arab high school students. Am J Orthod Dentofacial Orthop. 2004; 125(3): 373-378.

34. Feldens CA, Nakamura EK, Tessarollo FR, Closs LQ. Desire for orthodontic treatment and associated factors among adolescents in Southern Brazil. Angle Orthod. 2015; 85(2): 224-232.

35. Coyne R, Woods M, Abrams R. The community and orthodontic care. Part II: Community-perceived importance of correcting various dentofacial anomalies. Part III: Community perception of the importance of orthodontic treatment. Aust Orthod J. 1999; 15(5): 289-301.

36. Grzywacz I. The value of aesthetic component of Index of Orthodontic Treatment Need in the assessment of subjective orthodontic treatment need. Eur J Orthod. 2003; 25(1): 57-63.

37. Karaağaç E. 12-14 yaşlarındaki çocuklarda ortodontik tedavi ihtiyacı indekslerinin değerlendirilmesi. SDÜ Diş Hekimliği Fakültesi Pedodonti ABD Uzmanlık tezi. 2015

38. Phillips C, Bennett ME, Broder HL. Dentofacial disharmony: psychological status of patients seeking treatment consultation. Angle Orthod. 1998; 68(6): 547-556.

39. Mandall NA, McCord JF, Blinkhorn AS, Worthington HV, O'Brien KD. Perceived aesthetic impact of malocclusion and oral self-perceptions in 14-15-year-old Asian and Caucasian children in greater Manchester. Eur J Orthod. 2000; 22(2): 
175-183.

40. Sheats RD, McGorray SP, Keeling SD, Wheeler TT, King GJ. Occlusal traits and perception of orthodontic need in eighth grade students. Angle Orthod 1998; 68(2): 107-114.

41. Hamdan AM. The relationship between patient, parent and clinician perceived need and normative orthodontic treatment need. Eur J Orthod. 2004; 26(3): 265-271.

42. Bos A, Hoogstraten J, Prahl-Andersen B. Expectations of treatment and satisfaction with dentofacial appearance in orthodontic patients. Am J Orthod Dentofacial Orthop. 2003; 123(2): 127-132.
43. Ajayi EO, Ajayi YO. Attitudes to malocclusion in a Nigerian School Population. JMBR. 2006; 5(1): 16-23

44. Zreaqat M, Hassan R, Ismail AR, Ismail NM, Aziz FA. Orthodontic Treatment Need and Demand among 12- and 16 Year-Old School Children in Malaysia. OHDM. 2013; 12(4): 217-221.

45. Birkeland K, Bøe OE, Wisth PJ. Orthodontic concern among 11-year old children and their parents compared with orthodontic treatment need assessed by index of orthodontic treatment need. Am J Orthod Dentofacial Orthop. 1996; 110(2): 197-205. 